\title{
IMPACTO DOS AGROTÓXICOS SOBRE O MEIO AMBIENTE NO ESTADO DO PARANÁ-BRASIL
}

\author{
Mariana BAGGIO ANNIBELLI \\ Universidade Federal do Paraná - UFPR
}

O uso dos agrotóxicos, juntamente com outras tecnologias, como sementes com variedades geneticamente melhoradas de alto rendimento, expansão dos sistemas de irrigação e a mecanização intensa, fizeram parte de uma cadeia articulada de processos e atividades que modernizaram a agricultura mundial. Essas inovações integraram a segunda revolução agrícola, também chamada de Revolução Verde, que se constituiu em um novo ideário proposto pelos países centrais, a partir da Segunda Guerra Mundial. Posteriormente, essa cadeia articulada de processos e atividades passou a ser chamada de "pacote tecnológico" da agricultura contemporânea (ALTIERI, 2000).

O objetivo maior da Revolução Verde era o de elevar a produtividade dos cereais, uma vez que a humanidade passava por um significativo crescimento demográfico e imperava a necessidade de majorar o cultivo de alimentos, bem como da sua produção, visando evitar catástrofes alimentares, além de problemas sociais e políticos. Porém criou-se estreita dependência a essa tecnologia, fazendo-se aumentar os custos de produção na agricultura.

Agrotóxicos são substâncias químicas, ou mistura dessas substâncias, destinadas a prevenir ou controlar às pragas e organismos causadores de doença. Atualmente, no Brasil, sua utilizaçao é feita de maneira descontrolada, causando inúmeros impactos ao meio ambiente em geral.

O objetivo deste estudo é o de analisar as modalidades de impactos causadas pelo uso intensivo de agrotóxicos no Estado do Paraná, levando-se em conta os aspectos históricos e legais, tanto de âmbito estadual, como federal, propondo, ainda, medidas mitigadoras a serem adotadas, com o intuito de buscar aos poucos, uma agricultura sustentável e socialmente justa.

O Paraná está situado na região sul do Brasil e, apesar de ter sofrido na década de 90 um intenso processo de industrialização, destaca-se por sua vocação agrícola, com relevante participaçao no Produto Interno Bruto (PIB) nacional. 


\section{INTRODUÇÃO DO "PACOTE TECNOLÓGICO" NO BRASIL, COM OBJETIVO DE AUMENTAR A PRODUTIVIDADE.}

No Brasil foi a partir da década de 70 que a agricultura passou a sofrer grandes transformações, baseada principalmente nos ideais de "modernização agrícola". Ressalta-se que o escopo dessas mudanças apoiava-se basicamente na criação e difusão de uma nova tecnologia, criando novos conhecimentos e insumos, que por sua vez trairíam aumentos de produtividades e geração adicional de renda. A estratégia do desenvolvimento agrícola assentou-se, por sua vez, na intensificação de pesquisas que criassem novos conhecimentos e insumos, além da difusão dos mesmos a um maior número de agricultores, pois desse modo poder-se-ia aumentar a produção, ocasionando uma geração adicional de renda que impulsionaria o crescimento econômico (PAIVA, 1997).

Esas transformaçðes junto com a política de estímulo do crédito agrícola, associada às novas tecnologias, trouxe um grande impulso a várias culturas, principalmente às destinadas à exportação. Com o novo modelo agrícola, o crédito rural, através do Banco do Brasil, exigia dos produtores rurais a aplicação de recursos em tecnologias modernas, ao menos $15 \%$ do total apartado para o custeio de safras (PARANÁ, 1992).

Pacotes tecnológicos ligados ao financiamento bancário obrigavam os agricultores a adquirirem insumos e equipamentos, muitas vezes desnecessários. Essa política, acima de tudo, foi dirigida para o desenvolvimento de alguns setores industriais. Assim, a idéia da necessidade do uso de agrotóxicos foi modificada, ganhando cada vez mais espaço. Essas mudanças ocorreram acentuadamente na região Centro-Sul do Brasil (RÜEGG, 1991).

Muitos fatores contribuíram para que houvesse a expansão agrícola durante esse período, em especial nos estados de São Paulo e Paraná, principalmente em relação à disponibilidade de modernas tecnologias, tais como máquinas, equipamentos, fertilizantes e defensivos agrícolas, que contavam com preços favoráveis e estímulos, créditos fartos e juros subsidiados pelo Banco Central e Conselho Monetário Nacional, que facilitaram a sua ampla adoção no meio rural.

Hoje o Brasil é um dos países que mais consomem agrotóxicos. O Paraná é o segundo maior consumidor brasileiro, ficando apenas atrás de São Paulo, segundo dados da ANDEF - Associação Nacional de Defesa Vegetal, entidade que congrega as indústrias multinacionais fabricantes de agrotóxicos no país. A quantidade vendida ao Estado foi de 45.000 toneladas de agrotóxicos por ano (média dos anos de 1997, 1998 e 1999). Conforme dados do Instituto Brasileiro de Geografia e Estatística, IBGE, em pesquisa sobre o uso de Agrotóxicos nesse 
Estado, safra 1998/1999, havia cerca de 382.998 estabelecimentos agropecuários, dos quais 58\% utilizavam agrotóxicos.

A modernização da agricultura paranaense, segundo Dalton Áureo MORO (2000), deve ser considerada parcial, dolorosa e conservadora uma vez que limitou-se a algumas regiões, a alguns produtos específicos e a certas fases de organização da produção. Ademais, porque não rompeu com a tradicional concentração fundiária, isto é, a posse da terra. Inclusive porque concorreu para expoliar no campo milhares de pessoas ligadas às atividades agropecuárias, acentuando o êxodo e a miséria.

É inevitável considerar que se por um lado produziram-se benefícios, em especial quanto aos aspectos sanitário (eliminando epidemias e reduzindo os riscos de mortalidade em doenças propagadas por insetos) e agrícola (evitando perdas nas colheitas), os praguicidas converteram-se em sério problema por sua toxidade e, principalmente, por sua persistência no meio ambiente.

Em 1962, a americana Rachel Carson fez um alerta ao mundo em relação aos agrotóxicos, denominou-os "elixires da morte" em seu livro Primavera Silenciosa. Alertou ao mundo sobre os riscos que os seres humanos estavam correndo, uma vez em contato com essas substâncias "desde o momento em que é concebido, até o instante em que sua morte ocorre". Seu alerta surtiu efeitos, a partir de então inúmeras legislações de restrições e controle sobre os agrotóxicos começaram a ser elaboradas.

\section{ASPECTOS LEGAIS QUE REGULAM O USO DE AGROTÓXI- COS.}

Diante do descaso do governo federal brasileiro acerca dos problemas relacionados aos agrotóxicos, coube aos Estados legislarem acerca dessa matéria. Assim, a lei estadual $\mathrm{n}^{\circ} 7.747$ de 1983 foi sancionada com o intuito de regular a distribuição e comercialização de agrotóxicos e outros biocidas no território do Estado do Paraná. Determinou ainda, que a comercialização e da distribuição destes produtos ficarim condicionadas à cadastramento e autorização prévios da Secretaria de Agricultura e Secretaria de Interior. Submetendo, dessa forma, às restrições legais, também as indústrias importadoras, produtoras ou manipuladoras de agrotóxicos.

Em 1985 foi baixada a Portaria n ${ }^{\circ} 329$, onde o Ministério da Agricultura, com o intuito de resguardar a saúde humana e animal e o meio ambiente da ação dos agrotóxicos de alta resistência e periculosidade, proibiu, em todo o território nacional a comercialização, o uso e a distribuição dos produtos agrotóxicos organoclorados destinados à agropecuária. 
Em 1989, o Congresso Nacional aprovou a lei federal $n^{\circ} 7.802 / 89$, que dispõe sobre a pesquisa, a experimentação, a produção, a embalagem e a rotulagem, $o$ transporte, o armazenamento, a comercialização, a propaganda comercial, a utilização, a importação, a exportação, o destino final dos resíduos e embalagens, o registro, a classificação, o controle, a inspeção e a fiscalização de agrotóxicos, de seus componentes e afins.

Em seu artigo $2^{\circ}$ definiu agrotóxicos como os substâncias oriundas de processos físicos, químicos ou biológicos, destinadas ao uso em processos de produção, armazenamento e beneficiamento de produtos agrícolas, em pastagens, na proteção das florestas, nativas ou implantadas e também de ambientes urbanos, hídricos e industriais, cuja finalidade seja alterar a composição da flora ou da fauna, a fim de preservá-las da ação danosa de seres vivos considerados nocivos e também substâncias e produtos empregados como desfolhantes, dessecantes, estimulantes e inibidores de crescimento.

Estabeleceram-se, ademais, inúmeras restrições, visando acima de tudo, resguardar a saúde e bem estar das populações e do meio ambiente. Restringiu os tipos de embalagens a serem utilizadas, de modo a serem projetadas e fabricadas para impedir qualquer vazamento, evaporação, perda ou alteração de seu conteúdo. No entanto, não dispôs acerca da destinação final destas embalagens, falha esta que veio a ser suprida posteriormente, com a Lei $\mathrm{n}^{\circ} 9.984$ de 2000.

Antes da referida lei boa parte da responsabilidade de recolhimento, armazenagem, destinação final das embalagens vazias, fiscalização do cumprimento das normas e elaboração de campanhas educativas, cabia aos governos estaduais e municipais. Agora, conforme determinou seu artigo $6^{\circ}$, as empresas produtoras e comercializadoras de agrotóxicos, seus componentes e afins, são responsáveis pela destinação final das embalagens vazias dos produtos por elas fabricados e comercializados. Ao governo compete fiscalizar o cumprimento da legislação vigente e apoiar a elaboração das campanhas ou projetos educativos.

Para garantir a adequada destinação dessas embalagens utilizadas o Paraná possui quatorze unidades de recebimento e triagem. Antes, as embalagens eram destinas ao próprio meio ambiente, muitas vezes eram lançadas dentro de mananciais de água, ou abandonadas nas lavouras, jogadas à beira das estradas, ou queimadas à céu aberto, enterradas sem nenhum critério, ou comercializadas ilegalmente para reutilização e reciclagem sem controle. Chegava-se ao absurdo de utiliza-las para transporte e acondicionamento de alimentos.

Atualmente o Paraná tem o maior índice de recolhimento de embalagens do país. As unidades de recebimento receberam, nos dois primeiros meses de 2005, 2.463 toneladas de recipientes de defensivos agrícolas, índice 11,2\% superior 
ao mesmo período de 2004. No mês de fevereiro foram destinadas para reciclagem ou incineração 1.122 toneladas de embalagens e, nos últimos 12 meses (entre fevereiro de 2004 e janeiro de 2005), os volumes alcançaram a marca de 15.073 toneladas.

\section{IMPACTOS DIVERSOS DOS AGROTÓXICOS.}

Inseticidas, fungicidas, herbicidas e seus produtos de decomposição acham-se fartamente distribuídos na biosfera, sendo encontrados praticamente em todas as áreas do mundo, quer habitadas pelo homem ou não. Não há parte na Terra onde não existam pelo menos algumas moléculas dessas substâncias tóxicas em plantas, animais, solo, água e ar (PASCHOAL, 1979).

São produtos químicos, com vários graus de toxidade, utilizados para prevenir ou destruir completamente ácaros, insetos, roedores, fungos, ervas daninhas, bactérias e outras formas de vida. Conseqüentemente são altamente prejudiciais ao solo, a água, ao ar, à lavoura, à pecuária, aos alimentos vegetais e animais e as pessoas.

\subsection{Impacto sobre a atmosfera: amplos efeitos difusos.}

A atmosfera pode tornar-se contaminada localmente com o resultado de aplicações aéreas de agrotóxicos, na volatilização e co-destilação dos resíduos dos solos e, também, por erosão eólica. Alguns herbicidas com alta pressão de vapor volatilizam-se facilmente, mesmo durante as aplicações, principalmente aqueles contendo ésteres.

Vários inseticidas organoclorados com pressão de vapor relativamente elevada passam progressivamente do solo para a atmosfera. Se levados pelo vento, podem atingir áreas distantes. A aplicação aérea de pesticidas acarreta a perda de $10 \mathrm{a} 70 \%$ dos produtos aplicados, que são levados à deriva, contaminado outras áreas. As aplicações aéreas de pesticidas, efetuadas sem os cuidados necessários, poluem gravemente $\mathrm{o}$ ar e afetam as populações das cidades próximas às culturas tratadas (RÜEGG, 1991).

Ademais, em recente pesquisa RodRigues, CAMPANHOLA \& KITAMURA, (2002) diagnosticaram que os efeitos causados pelos fortes odores, decorrentes do uso desses insumos, causam desconforto às pessoas expostas em distintos niveis, desde franco a insuportável.

\subsection{Contaminação da água: ausência de meios adequados para um mo- nitoramento eficaz.}

Para controlar a qualidade da água é necessário o monitoramento de diversos indicadores, entre eles a avaliação dos resíduos de agrotóxicos. No Brasil vigora 
a portaria 36/Bsb/90 do Ministério as Saúde, que exige a análise de um conjunto de agrotóxicos, no entanto, inclui apenas 20 dos ingredientes ativos mais usados no Estado do Paraná. Porém, ANDREOLI \& FERREIRA (1998) afirmaram que o Estado do Paraná apresenta mais de 400 ingredientes ativos distribuídos em aproximadamente 700 marcas comerciais. Com base nesses dados é possível concluir que o controle desses agrotóxicos é ineficiente e não condiz com a realidade, pois dos vinte ingredientes ativos controlados, apenas cinco são comercializados no Paraná.

Por isso, em análises da qualidade da água em Curitiba, feitas pela Companhia de Saneamento do Paraná, SANEPAR, das 1539 amostras coletadas e analisadas, de água bruta e tratada, realizadas entre 1994 e 1998, não foram encontrados resíduos de agrotóxicos. Bem como ocorreu em Londrina, onde das 646 amostras coletadas, apenas 13 continham resíduos de agrotóxicos. No entanto, nenhuma das amostras coletadas, que continham agrotóxicos, estavam acima do limite permitido pela referida Portaria do Ministério da Saúde (ANDREOLI, 1999).

\subsection{Perda e contaminação do solo: seus efeitos a curto e médio prazos.}

A contaminação dos solos está intimamente relacionada com as técnicas de manejo do mesmo. A utilização abusiva de algumas tecnologias está causando perdas irrecuperáveis de territórios e um aumento da desertificação em extensas áreas.

O uso de alguns agrotóxicos muito persistentes pode provocar a contaminação dos solos, alcançando níveis altos de resíduos que podem afetar os cultivos seguintes. Os inseticidas clorados orgânicos (por exemplo: DDT, BHC, aldrin, dieldrin, clordano, heptacloro, e mirex - todos proibidos desde 1985) permanecem no solo por períodos longos, que variam de alguns anos a alguns decênios. Gradativamente eles são transferidos do solo para as culturas seguintes, passando também para as pastagens que ocupam posteriormente o solo cultivado. Desse modo, os resíduos passam também para a carne bovina e para o leite da vaca, através da alimentação (RÜEGG, 1991).

Os herbicidas podem também permanecer no solo, dependendo de vários fatores, por períodos de vários meses, até mais de um ano, interferindo diretamente e impedindo o desenvolvimento de novas culturas, correndo, inclusive o risco de serem lixiviados e de sofrerem escoamento superficial para as águas mais próximas.

Ademais, o uso intensivo de maquinária pesada causa a compactação do solo, mudando relativamente o perfil de suas camadas, principalmente quanto à capa 
orgânica, fundamental para a agricultura, por sua capacidade produtiva e seus nutrientes.

\subsection{Aumento do número de pragas resistentes: decorrente da seleção das espécies mais adequadas.}

Com o emprego de agrotóxicos, um certo número de pragas é destruído. Entretanto, sempre há indivíduos numa população que são naturalmente resistentes, quer por mecanismos fisiológicos, por exemplo, enzimas que degradam os inseticidas rapidamente, quer por particularidades morfológicas. Tal situação é ainda piorada se o produto for utilizado de modo excessivo e indiscriminado, pois mais rápido ainda é o desenvolvimento das populações resistentes.

Há um verdadeiro círculo vicioso dos pesticidas tornarem as pragas resistentes e novos produtos serem sintetizados para combater novas linhagens que, em pouco tempo, por pressão de seleção, tornar-se-ão também resistentes a esses novos produtos.

O uso indevido de pesticidas, assim como o seu transporte pela atmosfera, além de eliminar inimigos naturais das pragas das culturas, envenenam também insetos úteis como as abelhas e polinizadores de um modo geral (RÜEGG, 1991).

\subsection{Contaminação dos alimentos: causada pelo uso excessivo e irregular dos agrotóxicos.}

Como os agrotóxicos são altamente resistentes e bioacumuladores, resulta que o homem apresenta altos teores dessas substâncias em seu organismo. Isso se deve também ao fato de que os níveis de resíduos destes produtos estão acima da quantidade tolerada pela legislação vigente.

Em relação aos alimentos de origem animal, resíduos de organoclorados também são encontrados em todas as amostras pesquisadas, no entanto os teores estão cada vez menores. Apesar disso, tem-se que as partidas de carne com os resíduos mais baixos destinam-se à exportação. Essa política contribui para diminuir o nível de resíduos de inseticidas organoclorados na gordura, no sangue e no sistema nervoso central da população dos países industrializados, importadores dessa carne. Como as partidas com resíduos mais altos ficam no país, para consumo interno, esse tipo de atitude vem contribuindo para o aumento progressivo do teor de resíduos de inseticidas altamente tóxicos na população, prejudicando a saúde dos brasileiros.

Em recente pesquisa sobre a qualidade de alimentos consumidos no estado do Paraná, onde trabalharam conjuntamente a Secretaria de Estado da Saúde e a 
Secretaria de Estado da Agricultura e do Abastecimento, através do Programa de Análise de Resíduos de Agrotóxicos em Alimentos no Estado do Paraná PARA/PR, coordenado pela Divisão de Vigilância Sanitária de Alimentos do Departamento de Vigilância Sanitária e pela Divisão de Produtos do Laboratório Central do Estado, coletaram e analisaram, no período de junho de 2001 a junho de 2002, um total de 407 amostras de nove diferentes tipos de hortaliças e frutas oriundas da produção agrícola paranaense e de outros estados da federação.

Constatou-se que, do total de 407 amostras analisadas no período, 225 $(55,3 \%)$ apresentaram resíduos de agrotóxicos em algum grau. Chamaram a atenção os resultados encontrados para o tomate, maçã e morango, que se mostraram positivos para a presença de resíduos de agrotóxicos em mais de $90 \%$ das amostras, ademais, 55\% dessas amostras irregulares apresentaram resíduos de agrotóxicos não autorizados para a cultura, incluindo substâncias que estão proibidos no Brasil e $45 \%$ destas amostras possuíam resíduos acima dos valores limites permitidos pela legislação vigente. Dentre os princípios ativosencontrados irregularmente, os mais freqüentes pertencem ao grupo químico dos ditiocarbamatos, encontrados em $44,4 \%$ das 225 amostras e em cinco das nove culturas (alface, maçã, mamão, morango e tomate); seguido pelo clorpirifós etil que foi identificado em $9,3 \%$ das amostras irregulares, pelo dimetoato, em $8 \%$; metamidofós em $7,1 \%$ das amostras e endossulfan encontrado em $6,2 \%$.

\subsection{Contaminação humana: um risco eminete à população paranaense.}

No Paraná a série histórica de intoxicações por agrotóxicos evidenciou que: em primeiro lugar estão as ocorrências de intoxicações em virtude de contato laboral, com 5.445 mortes ocorridas entre os anos de 1986 a 1997, seguido por casos de tentativas de suicídio, com 2.184 casos e, em terceiro lugar, estão as intoxicações acidentais, com 1.262 casos. A este número, contudo, devem ser acrescidos outros casos de intoxicação que, embora causados por praguicidas, não são diagnosticados como tal, uma vez que o diagnóstico médico é difícil e os sintomas muitas vezes são confundidos com aqueles provocados por intoxicações alimentares. Uma vez que falta, além do controle rigoroso dos dados gerais, também o das mortes provocadas pela ingestão e inalação, inclusive dados sobre as mortes ocasionadas por doenças devido à exposição prolongada e com efeitos cumulativos, que não são registradas como causas de agrotóxicos.

Ressalta-se que a exposição constante a doses relativamente baixas de agrotóxicos acarreta o aparecimento de sintomas e sinais clínicos, após períodos que variam de algumas semanas até a vários anos. Alguns sintomas típicos são: lesões hepáticas; lesões renais; neurite periférica; ação neurotóxica retardada; atrofia testicular; esterilidade masculina; cistite hemorrágica; hiperglicemia, ou 
diabetes transitória; hipertermia; diminuição das defesas orgânicas, pela diminuição dos linfócitos imunológicamente competentes e conseqüente abaixamento do teor de anticorpos; fibrose pulmonar irreversível; hipersensibilidade e alergias; teratogênese; mutagênese e carcinogênese.

\section{MEDIDAS MITIGADORAS NECESSÁRIAS PARA REDUZIR OS FEITOS NEGATIVOS DOS AGROTÓXICOS.}

Há uma necessidade urgente de que medidas mitigadoras passem a serem adotadas, obrigatoriamente, por toda a sociedade, visando minimizar não somente os impactos anteriormente referidos, como também aqueles que até agora são desconhecidos. Dentro estas medidas, destacam-se algumas:

\subsection{Manejo integrado de pragas: uma prática ecológica e sustentável.}

Estudos anteriores demonstram claramente a inviabilidade da erradicação de artrópodes pragas. Uma filosofia de controle, baseada em sólidos princípios ecológicos cresceu em aceitação entre os entomologistas, acarologistas e sanitaristas de várias partes do mundo. A nova filosofia baseia-se no fato de que toda a humanidade deve aprender a viver com as pragas, já que erradicá-las é totalmente impossível.

Assim, o que se propõe é o uso de variedade e raças resistentes de plantas e de animais; o uso de predadores, parasitos, patógenos e competidores; o manejo genético das populações, pela introdução de genes letais e de genes que diminuem a adaptação das populações aos meios em que vivem, o uso de métodos de controle cultural, físico e mecânico, como temperatura, umidade, luz, som, etc., o que se baseia na ecologia e no comportamento das pragas; o uso dos antimetabólicos, de substâncias que impedem a alimentação das pragas, de hormônios e ferormônios e de substâncias atrativas e repelentes; o uso de técnicas de esterilização. Os praguicidas continuam a serem usados, mas com muito menor intensidade e com maior propriedade, apenas para manter as populações em níveis sub-econômicos (PASCHOAL, 1979).

Ressalta-se que, a erradicação total das pragas de uma região significaria uma simplificação ainda maior dos agroecossistemas, divido à eliminação drástica de de complexas teias alimentares de inimigos naturais e competidores. Isso, inclusive, possibilita a recolonização posterior da área por essas mesmas pragas ou por outras mais tardias, que seriam altamente favorecidas pelo desequilíbrio ecológico criado, o que tornaria necessária a aplicação repetida de produtos químicos que, de outra maneira, seriam dispensados. 


\subsection{Conservação dos solos: medidas eficazes que permitem a continui- dade da agricultura, em equilíbrio com o meio ambiente.}

É possivel com as práticas conservacionistas cultivar-se o solo sem depauperá-lo significativamente, quebrando assim um aparente conflito ecológico que existe entre a agricultura e o equilíbrio do meio ambiente. Essas práticas fazem parte da tecnologia moderna e permitem controlar a erosão, ainda que não anulem completamente, mas reduzindo significativamente.

Em áreas onde as práticas conservacionistas são aplicadas, resta evidente a harmonia da paisagem. As partes mais inclinadas, conforme dispõe a legislação brasileira vigente, devem ser ocupadas por florestas, onde a vida silvestre se desenvolve. Aos campos de cultivos não se indica o cultivo com a técnica "morro abaixo", mas sim em linhas contornando as rampas das encostas, visando evitar a lixiviação das terras aráveis para os rios. O objetivo é que os rios tenham águas limpas, livre de agrotóxicos, contaminação urbana e industrial, para tornarem-se piscosos e proporcionarem à população momentos agradáveis de lazer (LEPSCH, 2002).

Diante da grande problemática acerca do escoamento superficial das águas, que causam processos de lixiviaçao e erosão edáfica, uma medida que está sendo tomada, visando minimizar estes impactos por parte dos agricultores paranaenses é o uso de terraços, que interrompem ou diminuem a intensidade do escoamento das águas superficiais. Essa medida apesar de simples resulta salutar, uma vez que as práticas conservacionistas evitam o escoamento das enxurradas e, assim, permite-se que a água da chuva infiltra-se no solo, enriquecendo os mananciais subterrâneos, pois em não havendo o escoamento súbito, os rios deixam de ser perigosamente sobrecarregados, evitando inundações no campo de cultivo e nas cidades".

Além do terraceamento, outras práticas conservacionistas vem sendo aos poucos colacadas em prática pelos agricultores, como, por exemplo, aquelas que visam à eliminação ou controle das queimadas, adubações (incluindo calagens), rotação de culturas e práticas de caráter vegetativo, como o aumento da cobertura vegetal do solo através de reflorestamento, formação e manejo adequado de pastagens, cultivos e faixas, controle das capinas, faixas de árvores formando quebra-ventos e, inclusive, o plantio direto na palha da cultura anterior, visando não deixar o solo desprotegido, medida extremamente salutar e que atualmente está sendo utilizado em larga escala. 


\subsection{A necessidade de uma agricultura alternativa: proposta de sustenta- bilidade.}

Em oposição à agricultura dita moderna, que se caracteriza pela monocultura em grande escala (que marginalzou os pequenos agricultores, uma vez que esses não possuíam condições económicas para modernizarem-se), dependente de altas quantidades de insumos químicos e mecanização intensiva, faz-se necessário que se adote, cada vez mais, um outro tipo de agricultura que seja considerada sustentável, enfatizando a diversidade dos recursos naturais e o conhecimento local dos agricultores (Ho, 2004).

O uso de agroquímicos é inversamente proporcional à sustentabilidade da agricultura devido a duas razões: a primeira, porque essas substâncias são insumos externos que têm um alto custo ao produtor, impondo um investimento considerável de capital ao empreendimento agrícola; e a segunda razão porque eles sao importantes poluentes ambientais, quando usados inadequadamente ou em excesso (RODRIGUES, CAMPANHOLA \& KITAMURA, 2002).

A agricultura é sustentável quando é ecologicamente responsável, economicamente viável, socialmente justa, culturalmente apropriada, humanista e baseada em um enfoque holístico.

Trata-se, portanto, de uma nova abordagem que integra os princípios agronômicos, ecológicos e sócio-econômicos à compreensão e avaliação do efeito das tecnologias sobre os sistemas agrícolas e a sociedade como um todo. Uma abordagem ecológica incentiva os pesquisadores a penetrar no conhecimento e nas técnicas dos agricultores e a desenvolver agrosistemas com uma dependência mínima de insumos agroquímicos e energéticos externos (ALTIERI, 2000).

\section{CONSIDERAÇÕES FINAIS.}

Diante da realidade apresentada, dos problemas jurídicos, sociais e ambientais decorrentes da falta de consciência e do uso descontrolado e irresponsável de agrotóxicos por parte dos agricultores, torna-se cada vez mais necessária a busca e aplicação de um modo de vida sustentável, que não obstante vise majorar a produtividade, tenha como escopo a melhora da qualidade de vida de toda a população, combatendo a miséria rural, fixando o homem no campo, dando condições de bem estar e de prosperidade a toda sua família.

Esta proposta de sustentabilidade vem cada vez mais ganhando força e credibilidade no território brasileiro. Suas raízes estabeleceram-se a partir da Conferência das Nações Unidas sobre Meio Ambiente e Desenvolvimento, em 1987 e da Rio-92, desde então são diversas as organizações governamentais ou não 
(ONGs), que estão trabalhando com o intuito de buscar novas estratégias de desenvolvimento e manejo integrado de recursos.

\section{REFERÊNCIAS BIBLIOGRÁFICAS.}

ABramovay, R. (2001): «A agricultura brasileira na contra mão». Publicado no jornal Gazeta Mercantil, em 10/01/01.

Altieri, M. (2000): Agroecologia: a dinâmica produtiva da agricultura sustentável. 2 ed. Porto Alegre, Editora da Universidade UFRGS.

ANDREOLI, C. (1999): «Avaliação dos níveis de agrotóxicos encontrados na água de abastecimento nas Regiões de Curitiba e Londrina». Curitiba, SANARE-Revista Técnica da Sanepar.

ANDREOLI \& FERREIRA. (1998): «Levantamento quantitativo de agrotóxicos como base para a definição de indicadores de monitoramento de impacto ambiental na água». Curitiba, SANARE-Revista Técnica da Sanepar, v.10.

BRASIL (1997): Manual de vigilância da saúde de populações expostas a agrotóxicos. Brasília, Organização Pan-americana da Saúde. Ministério da Saúde. Secretaria de Vigilância Sanitária.

CARSON, R. (1964): Primavera silenciosa. São Paulo, Melhoramentos.

COlborn, DumANOSKI \& MYERS. (2002): O futuro roubado. Porto Alegre, L\&PM.

DeUS, S. (2002): «Nova lei dos Agrotóxicos». In Revista do CREA-PR, n. 6.

DREW, D. (1994): Processos interativos homem-meio ambiente. 3ed. Rio de Janeiro, Bertrand Brasil.

EHLERS, E.: «O que se entende por agricultura sustentável?» In VEIGA, José Eli (org.). Ciência ambiental, primeiros mestrados. São Paulo, USP.

GelminI, G. (1991): Agrotóxicos, legislação básica. Volume I. Campinas, Fundação Cargil.

GONÇALVES NETO, W. (1997): Estado e agricultura no Brasil: política agrícola e modernização econômica brasileira 1960-1980. São Paulo, Hucitec.

Ho, M. (2004): Em defesa de um mundo sustentável sem transgênico. São Paulo, Expressão Popular.

LEPSCH, I. (2002): Formação e conservação dos solos. São Paulo, Oficina de Textos.

MORAGA \& SCHINEIDER (2003): Biocidas: suas propriedades e seu histórico no Brasil. Instituto de Geografia - UFU.

MORO, D. (2000): «A modernização da agricultura paranaense». In Geografia social e agricultura. org. Villalobos, J. Maringá, Programa de pósgraduação UEM.

PARANÁ (1992) Agrotóxicos, coletânea sobre a situação do Paraná. Curitiba, Secretaria especial para assuntos de meio ambiente. 
PASCHOAL, A. (1979) Pragas, praguicidas e a crise ambiental: problemas e soluções. Rio de Janeiro, FGV.

POLTRONIÉRI, L. (1998): «Riscos ambientais e custos sociais do uso de praguicidas na agricultura». Revista RA'EGA:o espaço geográfico em análise, n.2, ano II, Curitiba, UFPR, p. 167-211.

RODRIGUES, CAMPANHOLA \& KITAMURA. (2002): Avaliaçao de impacto ambiental da nova tecnologia agropecuária: um sistema de avaliaçao parao contexto institucional de P\&D. Caderno de Ciência e Tecnologia, Brasília, v.19.

RÜEGG, E. et all. (1991): Impacto dos agrotóxicos sobre o meio ambiente, a saúde e a sociedade. 2 ed. São Paulo, Cone.



